\title{
Modelling the impact of alternative educational qualifications on the New Zealand higher education system
}

\author{
Stephen Marshall \\ Victoria University of Wellington New Zealand
}

\begin{abstract}
Agent-based modelling provides a mechanism by which complex social phenomena can simulated in order to identify how particular features arise from causes such as demographics, human preferences and their interaction with policy settings. The NetLogo environment has been used to implement a simulation of the New Zealand higher education system, using historical data to calibrate model settings to mirror those of the real-world system. This simulation is used to explore how the introduction of an alternative qualification and education paradigm might disrupt established patterns of education and employment.
\end{abstract}

Keywords: Agent based modelling, Simulation, Higher education change, Microcredentials.

\section{Introduction}

Higher education, even before the disruption caused by the COVID-19 Pandemic, is experiencing significant pressure to evolve and respond to a complex array of social, economic and political forces, enabled and catalysed by technology (Marshall, 2018). Major issues include the affordability of higher education as costs continue to grow much faster than the underlying inflation rate in many countries and debt is increasingly an issue for many students who are failing to see a significant wage premium for their qualifications. The traditional qualification and skills development models are increasingly criticised as not meeting the needs of the economy (Calonge, Shah, Riggs \& Connor, 2019; Dlabajová \& Nekov, 2017; Ehlers, 2020; Kinash \& Crane, 2015; Zaber, Karoly, \& Whipkey, 2019) and a narrative of disengagement by employers is widely cited (Ernst \& Young, 2015) if not necessarily consistent with the evidence from employment data and employer research (Gallagher, 2016). Governments, such as that in New Zealand, are developing mechanisms that promote a focus on employability by education providers, and others are using funding as a blunt instrument to focus higher education on the needs of specific industries. The inability of higher education systems to scale affordably for school leaver populations is further exacerbated by the increasing expectation of adult learners to build and sustain their knowledge and skills while in employment in order to further their careers and respond to changing employment conditions.

Many have proposed that alternative mechanisms are needed to meet the changing educations needs of modern society. These are increasingly defined by their use of digital technologies as replacements for various affordances and systems traditionally used by universities. Historically alternative education and qualification models have included open education as exemplified by the creation of the Open University (Dorey, 2015; Woodley, 2007) and more recently by such organisations as the OERu (Mackintosh, 2016; McGreal, Mackintosh \& Taylor, 2013), simply moving existing institutional models online as virtual universities operating traditionally framed qualifications or as blended learning mixing face to face and online experiences, commercially operated private provision without the wider social mission of the University, and the Massive Online Open Course (MOOC) as a pure education experience divorced from credentialing in its initial conception. More recently the microcredential has been suggested as the latest silver bullet that will address the challenges of enabling higher education sustainably and at scale throughout adult lifetimes and in a wider range of contexts than historically enabled by universities.

A microcredential has been defined as "a certification of assessed learning that is additional, alternate, complementary to or a formal component of a formal qualification" (Oliver, 2019, p. i). A similar focus on formal recognition is apparent in the definition of Kato, Galán-Muros and Weko (2020) "credentials that are not recognised as standalone formal educational qualifications by relevant national education authorities."

Although the tensions between the regulatory environment for education and the deployment of these alternative credentials is still very much in evidence in many countries (Expert Panel for the Review of the Australian Qualifications Framework, 2019; NZQA, 2020a; Bolton, 2019) there are already a growing number of examples of microcredentials and similar alternative credentials including MOOCs and associated credentials which are 
packaged into forms similar to traditional qualifications (Maxwell \& Gallagher, 2020; Oliver, 2019). Shah (2019) has identified 50 different MOOC offerings packaged as degree programs by international universities.

Microcredentials have been suggested as a mechanism for:

- reducing the opportunity cost by allowing for education while in employment or flexibly around other commitments, including unbundling into smaller pieces (Craig, 2015; Maxwell \& Gallagher, 2020);

- recognition of prior learning, and thus reducing the time and cost needed to complete qualifications (Buban, 2017; Kato, Galán-Muros \& Weko, 2020; Milligan \& Kennedy, 2017)

- providing a mechanism for documenting a wider range of learner outcomes or graduate attributes, and creating a portfolio of achievement for employers that can lead to greater opportunities for jobs and increased movement between jobs (Brown \& Kurzweil, 2017; Gallagher, 2018; Hadavand, Gooding, \& Leek, 2018; Kato, Galán-Muros \& Weko, 2020; Milligan \& Kennedy)

- providing evidence of ongoing professional development recognised through increased salaries and/or as influence on length of employment (Gallagher, 2018; Kato, Galán-Muros \& Weko, 2020; Milligan \& Kennedy).

The success or otherwise of alternative higher education models, and the real-world impact of the plausible benefits noted by proponents and researchers in such lists, is typically difficult to assess in advance. History is filled with examples of "innovations" whose limitations have only been widely recognized in hindsight. Examples include the many failed virtual universities from the first decade of this millennium, large private providers such as the University of Phoenix Online. Part of the reason for these failures not being apparent is the complex interplay of human behaviour, economics and politics that frames the operation of national higher education systems. This complexity is evident in the difficulty that the European Union has encountered in the implementation of the Bologna agreement and in operation of an integrated higher education system operating in multiple countries.

Although the best simulation of any system is the real world, it is an expensive proposition to learn from changes to a system that has a significant impact on economies and individual lives. An alternative is to use agent-based modelling to create dynamic simulations of a simplified version of a national higher education system, focusing on aspects that generate agent behaviours which correlate with a real-world system. This paper describes how agent-based models can be created and used to test various policy and other choices for alternative qualifications using the New Zealand tertiary education system as a reference point. It will start with a description of agent-based modelling as an approach, provide a summary overview of the creation of a model using the New Zealand education system as a reference point, and then explore a set of hypotheses regarding how alternative qualifications might be implemented using the agent-based model to simulate these and illustrate potential outcomes that can be considered in real-world policy making and evaluations.

\section{Agent-based modelling}

“All models are wrong, but some models are useful” (Box, 1979).

Wilensky and Rand (2015, p. 14) define agent-based modelling as "a computational methodology that enables one to model complex systems." Such models have been used to explore a wide range of social policy issues including many with direct relevance to academic work and university management such as the impact of gender on career progress in universities (Bullinaria, 2018), wellbeing (Thron, 2016), college admission processes and their impact on systematic inequality (Reardon, Kasman, Klasik \& Baker, 2016), and even the publication strategies adopted by academics (Gu, Blackmore, Cornforth \& Nesbitt, 2015).

Agent-based models can be used to create artificial societies (Builder \& Bankes, 1991) that enable researchers to explore how changes to various policy settings might affect the operation and outcomes of a social system (Gilbert \& Troitzsch, 2005). Within these models underlying choices are made by the agents applying a small number of simple behaviours responding to the environment being modelled and generating complex system outcomes arising from individual choices enacted between agents (Huston, 1988) rather than in response to a specific equation or predefined set of instructions.

Agent-based modelling in the social sciences has deep roots (Epstein \& Axtell, 1996), starting with the work of computational pioneer John von Neumann's work on cellular automata (von Neumann, 1966), and expressed substantially first in the work of Schelling exploring racism and segregation $(1969 ; 2006)$. Schelling was able to 
show through models that segregation in housing arises even when very little racial preference is expressed by individuals. Figure 1 illustrates the operation of model developed from Schelling's work implemented in the NetLogo environment (Wilensky, 1997). In this model there are two types of agent, orange and blue, who both prefer to be located such that at least $30 \%$ of the neighbouring eight squares are occupied by agents with the same colour. Agents assess their environment and if they can't meet that criterion, they move to an available empty square. Starting with a random distribution on the left, the model iterates very rapidly to a pattern like that on the right, with clearly segregated clusters emerging. Simply adjusting that $30 \%$ criterion up or down generates stronger or weaker segregation patterns. This model illustrates the idea that a complex phenomenon can arise from a very simple rule as well as the reality that this does not in itself provide a direct prediction of what patterns might arise in specific communities, rather it supports the idea that segregation arises even in the presence of comparatively tolerant groups.
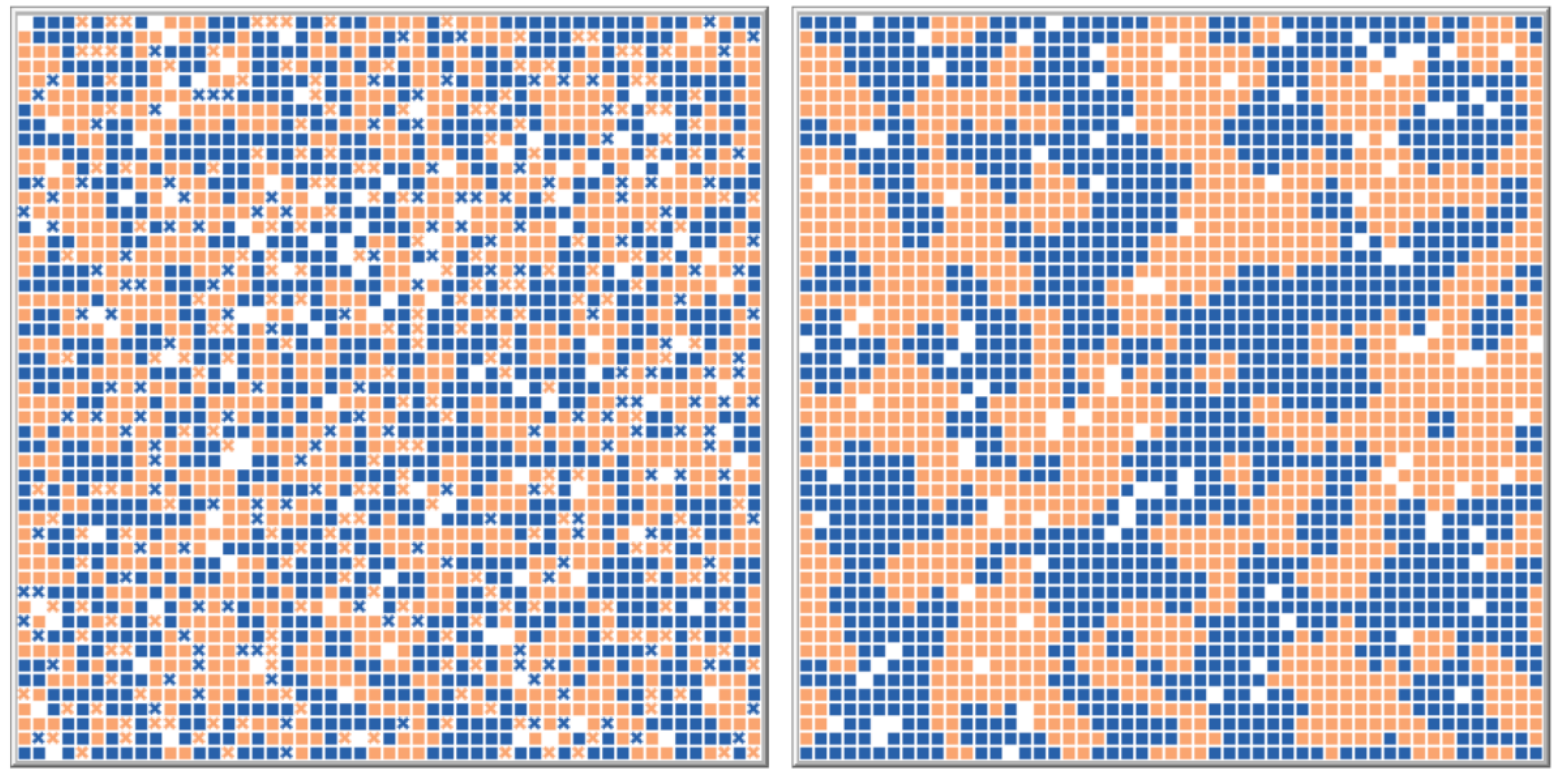

Figure 1: Agent-based model exploring segregation. Initial state on the left, outcome of the simulation on the right

The models created use agents with properties and pre-defined simple behavioural rules that are represented in some way as they engage with an environment defined by a set of properties that mediate or stimulate the agent's application of its behavioural rules. Unlike formal economic or mathematical analysis of complex systems, agent-based models have the advantages of using discrete representations that are more easily comprehendible by a wider audience of researchers and stakeholders, of being able to more closely match realworld situations, and are able to be easily modified and visualized meaning that the system can be critiqued and understood rapidly as different rules or properties are explored.

An important point to emphasise is that the models are not intended to predict the future as any predictive power is subject to the data used to shape the model and its assumptions. Rather, these models provide tools that can be used to describe historical patterns and to explain features that may generate future patterns. There are two main approaches used to design models for simulations, exploratory modelling and phenomena-based modelling (Wilensky and Rand, 2015). Exploratory modelling looks for emergent behaviours arising from the application of behavioural rules by the agents, while phenomena-based modelling uses a reference pattern of real-world evidence to drive the identification of a set of rules for agents that generates a similar outcome, thus generating a potential explanation for the emergence of that phenomenon in the real world. In the next section, the development of a phenomena-based model of higher education is described, which will then be used in an exploratory way to examine alternative credentials in the section that follows.

\section{Creation of a phenomena-based agent model of the New Zealand tertiary education system}

The model used in this paper is designed to behave similarly to the New Zealand tertiary education system with 
regard to the types of qualifications offered, the scale of provision, and its relationship to the economy and society at large. Implemented in NetLogo (Wilensky, 1997) the main visualisation interface is shown in Figure 2.

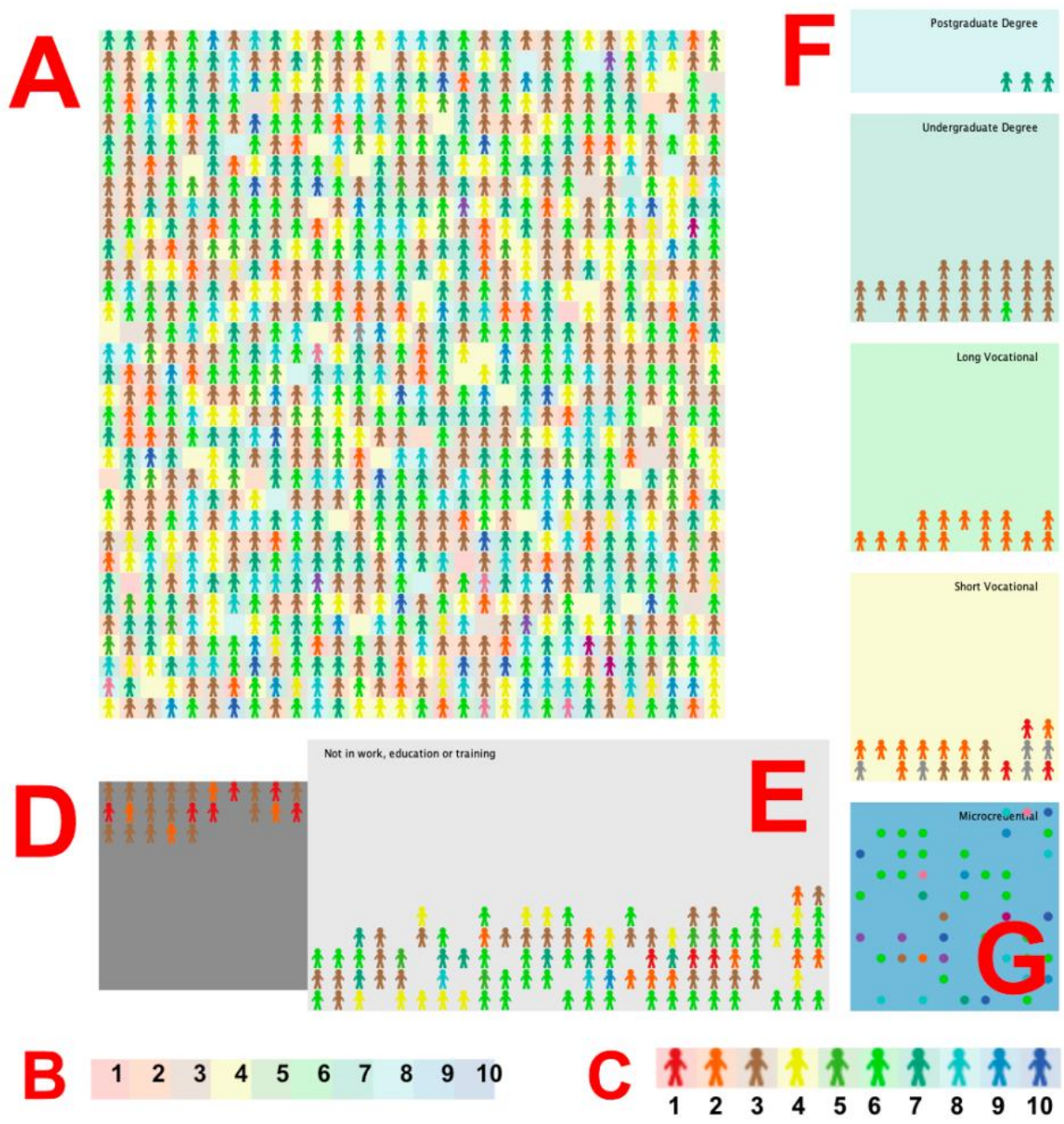

Figure 2: Model visualization interface in NetLogo

The largest area of the interface is used to display the range of spaces that agents occupy when they are employed (A). Each square within this area represents a sector of society, abstracting the employment of approximately 3500 people. The colour of the squares conveys the educational requirements of the employment in that square (B) according to the New Zealand Qualifications Framework (NZQF; NZQA, 2020b) with the distribution of these randomly specified according to a distribution that matches the job structure of the New Zealand economy (Table 1).

The small people shown in each square represent agents, themselves colour coded as per the highest level of qualification they have under the NZQF (C). The model maintains a population of 1100-1200 agents reflecting the working population of 15-65 year old New Zealanders (Table 1).

The model operates using ticks or time that are analogous to years. Each tick, the agents are aged one year, those reaching 65 are retired from the model, and a new set of agents representing school leavers are randomly generated to maintain a stable demographic (D). Every tick, each agent evaluates its state and chooses whether to seek employment or education. Agents have a randomly assigned set of preferences for both work and education that influence this choice. A simplified outline of the choice algorithm is:

If currently in education for multiple years continue:

Continue to complete education 
Otherwise:

If employed, make a decision about career advancement

If only recently employed, collect a salary and build wealth

If employed for longer than preferred, look for alternatives

If no better jobs available get more education if jobs exist

If not employed, consider your options

If the preference for education > preference for employment

Look for an available education option that builds on existing qualifications

Use debt to meet the costs if available, otherwise use personal wealth

If Employment preferred, no education options available, try to find a job

Find any job that is of the level of highest qualification or close to it

Agents that fail to find employment or education are placed in the not in work, education or training space (E). The various options for education are shown on the right side of the interface (F). The model recognises four existing qualification models and also a space for an alternative model that can operate under different modes to test various policy options $(\mathrm{G})$. The small dots in the microcredential space indicate that a agent has chosen to obtain a qualification during the current year. The four existing qualification models are based on the New Zealand tertiary system and include postgraduate degrees ( 1 year masters and 3 year doctorates), undergraduate degrees ( 3 years), long vocational apprenticeships ( 5 years), and short (1 year) vocational qualifications. All of these are aligned to the NZQF levels. As the model is simulating a large population with each agent and to simplify the focus of analysis, no attempt is made to simulate differences in individual ability, or to account for retention and completion rates in study.

Table 1: Reference pattern evidence

\begin{tabular}{|l|l|l|}
\hline Population size & New Zealand Population 15- 64 & Stats NZ Infoshare http://archive.stats.govt.nz/infoshare/ \\
\hline Population growth & NZ Fertility rate & Stats NZ Infoshare http://archive.stats.govt.nz/infoshare/ \\
\hline $\begin{array}{l}\text { Tertiary attainment } \\
\text { rates }\end{array}$ & $\begin{array}{l}\text { Attainment for working adult } \\
\text { population }\end{array}$ & $\begin{array}{l}\text { Statistics New Zealand Household Labour Force Survey } \\
\text { http://archive.stats.govt.nz/infoshare }\end{array}$ \\
\hline $\begin{array}{l}\text { Wealth } \\
\text { distribution }\end{array}$ & NZ Gini 0.349 in 2014 & $\begin{array}{l}\text { OECD Income inequality } \\
\text { https://data.oecd.org/inequality/income-inequality.htm }\end{array}$ \\
\hline $\begin{array}{l}\text { Unemployment } \\
\text { rate }\end{array}$ & $\begin{array}{l}\text { OECD Unemployment rate } \\
\text { https://data.oecd.org/unemp/unemployment-rate.htm } \\
\text { OECD Long-term unemployment rate } \\
\text { https://data.oecd.org/unemp/long-term-unemployment- } \\
\text { rate.htm }\end{array}$ \\
\hline $\begin{array}{l}\text { Salary ranges } \\
\text { for jobs }\end{array}$ & $\begin{array}{l}\text { Decile groups as per IRD data } \\
\text { IRD Income distribution of individual customers 2001 to }\end{array}$ \\
\hline $\begin{array}{l}\text { Worker } \\
\text { mobility }\end{array}$ & $\begin{array}{l}\text { Approx. 60\% of workers stay } \\
\text { https://www.ird.govt.nz/about-us/tax-statistics/revenue- } \\
\text { in the same job each year } \\
\text { refunds/income-distribution }\end{array}$ \\
$\begin{array}{l}\text { Coleman and Zheng, 2020; Borland and Coelli, 2017 } \\
\text { Australia data suggest 25\% } \\
\text { stay 1yr or less, 50\% 1-10 } \\
\text { years; 25\% more than 10 } \\
\text { years }\end{array}$ & \\
\hline
\end{tabular}

The reference pattern used to calibrate the settings embedded into the model is based on evidence summarised in Table 1. The correlation of the model with this reference pattern was tested by repeatedly running it for 1000 years to see how the agent behaviour patterns stabilised. Figure 3 shows the outcomes of 10 such calibration runs aligned against the reference pattern data for New Zealand from 2014-2019. In each case a new random seed value was used and recorded for verification purposes. 


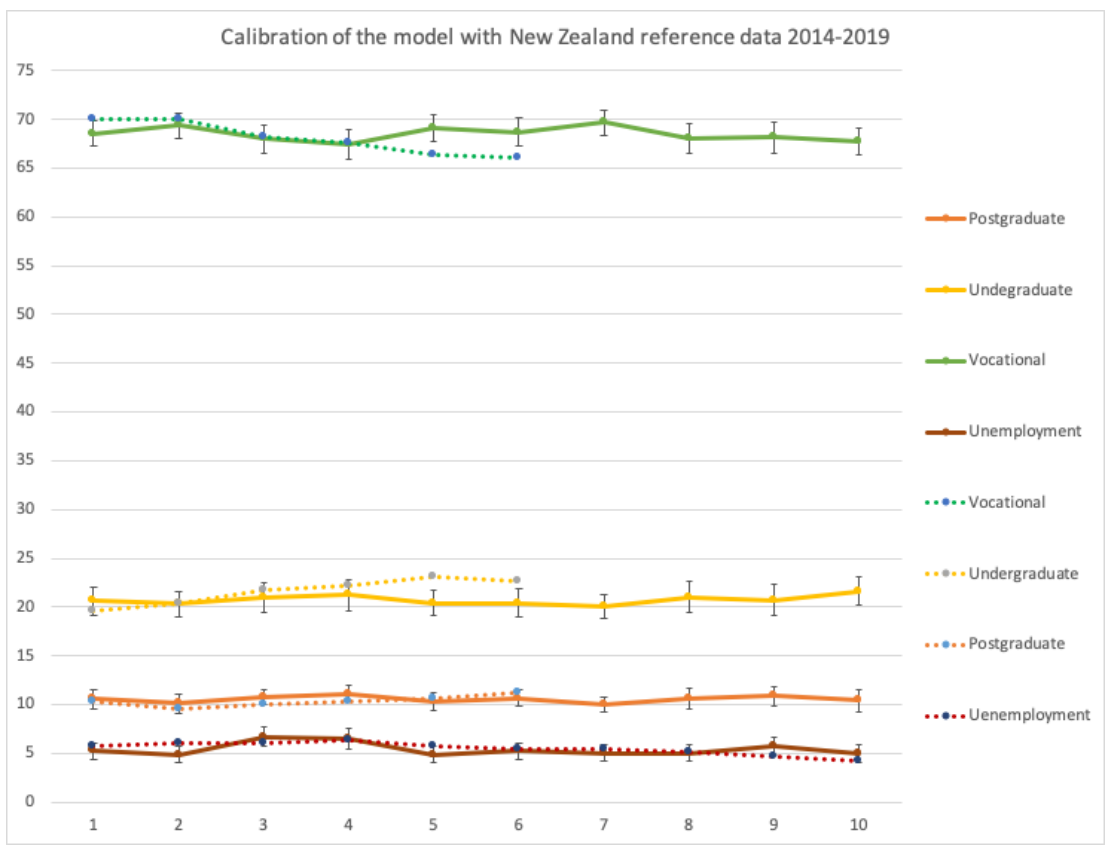

Figure 3: Calibration with Reference Pattern for New Zealand 2014-2019 (dotted line is real-world data)

Having established the model generated a pattern of agent activity with outcomes that correlated with the reference pattern it was then possible to add features that explore how this system changes when an alternative credential model is introduced.

\section{Modelling the impact of different policy settings and behaviours for alternative credentials}

As was discussed in the introduction, microcredentials are suggested to have a positive outcome in five different ways:

1. reducing the opportunity cost of gaining qualifications by providing flexibility and allowing education while in employment;

2. reducing the direct costs of obtaining education, both in terms of finance and time taken through recognition of prior learning;

3. increasing the chance of gaining employment and making it easier to move jobs, generating increases in earnings;

4. providing evidence of ongoing professional development recognised through increased salaries;

5. influencing choices made regarding the length of employment through increased personal satisfaction.

Each of these was implemented in the model and the impact on qualification attainment rates over the population, participation in employment, and individual outcomes such as salary, aggregate wealth and the number of jobs held over a lifetime examined. In each case the agents were randomly assigned into one of two conditions: wanting or not wanting microcredentials, and two populations were compared over the 1000 ticks for a given run using a two-tailed $\mathrm{T}$ Test with unequal variance.

\section{Reducing the opportunity cost of qualifications}

This experiment modified the model to reduce the opportunity cost of gaining qualifications by providing flexibility and allowing education while in employment. Microcredentials in this version were able to be gained at minimal cost and once three ticks worth had been collected, they could be used to gain an additional level of education above the previous highest qualification for the agent. This allowed movement within the vocational qualification levels (1-6) or within degree levels (7-9) but not between the two. Figure 4 shows the summary overview of the two configuration outcomes. 
A.

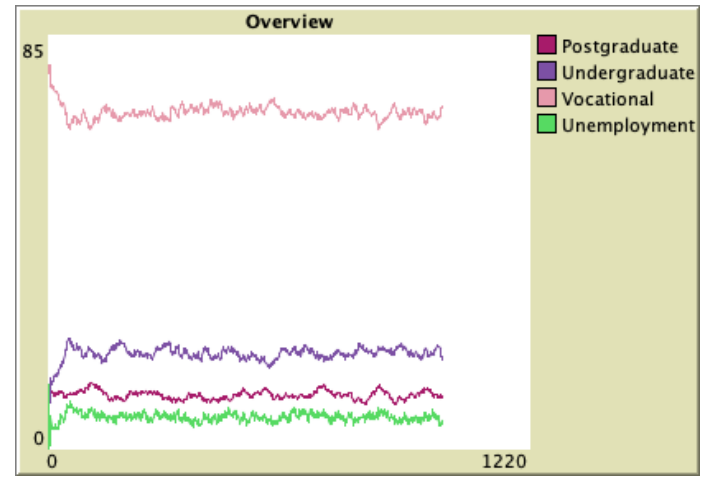

B.

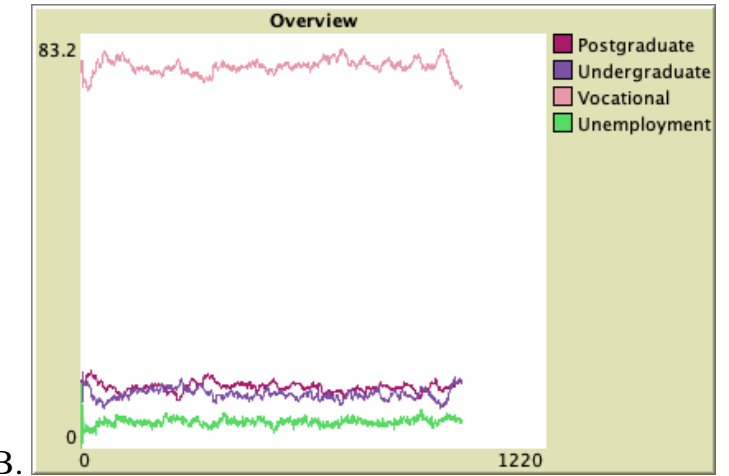

Figure 4: Overview of reducing the opportunity cost. A: reference pattern B: microcredentials for qualifications

Part A of Figure 4 is an example of the reference pattern. Part B is an example of the tested hypothesis which shows that allowing microcredentials to be used to gain qualification levels while in employment has seen the population level of vocational qualifications increase significantly from $68.5 \%$ (mean, SD 1.4) to $76.8 \%$ (SD 1.4), and undergraduate degree levels correspondingly dropped to $10.9 \%$ (SD 1.1) from 20.8 (SD 1.4). Both changes have $\mathrm{p}$ values $<<0.001$. The population maintained a range of qualification achievement and no significant difference in the outcomes for the two sub-groups of agents gaining or not gaining microcredentials was observed, nor was there a significant impact on unemployment or on the levels of postgraduate education.

\section{Reducing the direct costs of qualifications}

Microcredentials have started to be used as an entry point to longer qualifications through recognition of prior learning processes. This is tested in the model by allowing microcredentials obtained in either workplaces or while unemployed to be used to reduce the time and cost obtaining multi-year vocational or degree qualifications by 1 year. The results are shown in Figure 5. No change in the model outcomes either for the population measures or individual outcomes of agents where the change was applied. As the student debt provisions could influence this by masking the value of such measures, the model was also run with a reduced 2 year debt setting instead of the current New Zealand 5 year provision (Figure $5 \mathrm{~B}$ ) and this was also found to show no effect from having microcredentials available compared to a control with the same setting (although this did show a significant impact on the level of postgraduate education in the model (down from $12.2 \%$ to $7.4 \%$ with SD or $0.9 ; \mathrm{p}<<0.001)$.

A.
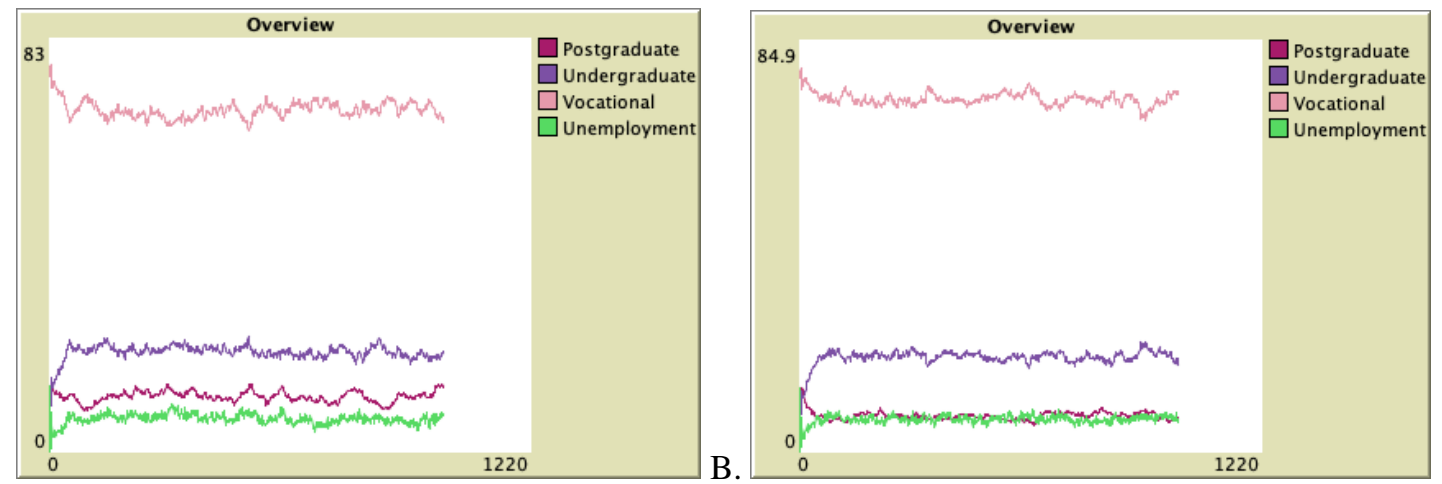

Figure 5: Overview of reducing the direct cost of qualifications. A: 1 year recognition of prior learning with normal debt settings $B$ : as with $A$, but with a 2 year debt setting

\section{Increasing employment chances}

This experiment modified the model to take account of microcredentials when sorting the agents to choose jobs. Agents were sorted by highest qualification and then those with the most microcredentials were able to take first choice of the available jobs, in effect changing the model so that employers would prefer those agents over those with fewer or no microcredentials. No change was visible at the overall population level, but simply 
making this change saw those agents with microcredentials gaining a significantly higher ( $<<<0.001)$ top salary (24.3, SD 8.9) than those without (20.8, SD 11.5) during their careers.

\section{Increasing salary while employed}

The impact of microcredential as providing evidence of ongoing professional development recognised through increased salaries was done. The model was changed such that after a period of employment of three years, the agent's salary would be increased to a randomly determined amount similar to that for a job created in the model at 1 level of education higher than would normally apply. Again, this had no effect on the overall population, but very significant (p < 0.001$)$ increase in salary (39.4, SD 10.5 vs 22.2 SD 11.9) and accumulated wealth (65.5, SD 34.2 vs 57.6 SD 34.2) were observed for agents using microcredentials. Another significant consequence was a substantial reduction in the number of jobs $(2.1$, SD 1.1 vs 3.4, SD 1.8, p $<$ 0.001) an agent held over their lifetime.

\section{Reducing desire to leave while employed}

Microcredentials are also proposed as offering great satisfaction for employees, encouraging their retention by reducing the propensity to look for better work elsewhere. This was implemented by reducing the times agents looked for other work during their preferred length of employment, instead replacing them with microcredential use. As with the previous change using salary increases as an inducement this led to a reduction in the total number of jobs over an agent's lifetime if they used microcredentials (2.0, SD 0.9 vs 3.6, SD 1.9) but unlike previously this loyalty also resulted in a substantial reduction in accumulated wealth (20.9, SD 22.6 vs 63.1, SD $36.1)$ and a lower peak salary (20.2, SD 9.4 vs 23.9, SD 12.3).

\section{Discussion and Conclusion}

The five experiments conducted suggest that microcredential introductions are likely to have a mixture of consequences for the providers of qualifications (as reflected in the overall patterns of qualification attainment) and for individuals (as suggested by the outcomes for populations of agents).

Reducing the opportunity cost of gaining qualifications by providing flexibility and allowing education while in employment had the interesting result of greatly increasing the proportion of agents with vocational qualifications as their highest attained, while significantly decreasing the numbers with undergraduate (but not postgraduate) degrees. This seems to reflect a pattern of behaviour where agents moved through vocational jobs in a sequential manner as they gained qualifications, opening up spaces for school leavers as they did so. In effect creating a dynamic where options other than formal education were immediately available.

In contrast, the strategy of using microcredentials to reduce the time and cost of gaining formal qualifications had no impact in this model. The implication is that these are not drivers affecting outcomes for the agents, with the benefits of gaining access to jobs dominating the behaviors. Notably testing the use of recognition of prior learning with microcredentials to reduce the time and cost of gaining a multi-year qualification is equivalent to testing the model against the New Zealand Governments "Fees Free" policy that removes fees for the first year of tertiary study, a result that is consistent with the minimal impact of that policy reported in the literature (Hipkins, 2017).

The importance of the job as a driver of outcomes is illustrated by the impact on salaries that resulted from simply moving agents to the front of the queue for job prospects. This is also consistent with the impact that having qualifications from prestigious institutions is seen to have, and suggests a fruitful area for future modelling as it arises from a very minimal change in the model's behaviour.

Finally, the two experiments on retention illustrate that microcredentials can change outcomes for agents significantly in this model, but that the differences can be either positive or negative depending on the way that the microcredential is used to motivate their behaviour.

It is important to note that the model used here is a greatly simplified abstraction. The model was developed to focus on key features of a tertiary education qualification model and necessarily does not include many important real-world aspects. These include the variety of different providers offering similar qualifications and their reputations, costing models, and location; the variety of qualification subject areas and their relationship to 
specific employment and community contexts; shifting demand for skills including the potential creation of a two-speed employment market with low skilled and highly skilled jobs increasingly dominating; issues of systematic inequality and access to education, social capital and family support; demographics and the aging New Zealand workplace; regional distribution of provision and the impact of migration, international and transnational education. All of these offer fruitful spaces for further investigation in the future.

\section{References}

Bolton, R. (2019). Micro credentials a 'jungle' in need of reform. Financial Review, August 5, 2019. https://www.afr.com/policy/health-and-education/micro-credentials-a-jungle-in-need-of-reform20190801- p52cul

Borland, J., \& Coelli, M. (2017). Are robots taking our jobs? Australian Economic Review, 50(4), 377397. https://doi.org/10.1111/1467-8462.12245

Box, G. (1979). Robustness in the strategy of scientific model building. In R. Launer \& G. Wilkinson (Eds.), Robustness in statistics (pp. 201-236). Washington, DC: United States Army Research Office.

Brown, J., \& Kurzweil, M. (2017). The complex universe of alternative postsecondary credentials and pathways. Cambridge, MA: American Academy of Arts \& Sciences. Retrieved from https://www.amacad.org/content/publications/publication.aspx?d=22786

Buban, J. (2017). Alternative credentials: Prior learning 2.0. Online Learning Consortium. https://files.eric.ed.gov/fulltext/ED603798.pdf

Builder, C. \& Bankes, S. (1991). Artificial societies: A concept for basic research on the societal impacts of information technology. RAND Corporation. https://www.rand.org/pubs/papers/P7740.html

Bullinaria, J. (2018). Agent-based models of gender inequalities in career progression. Journal of Artificial Societies and Social Simulation, 21(3) 7. https://doi.org/10.18564/jasss.3738

Calonge, D.S., Shah, M.A., Riggs, K., \& Connor, M. (2019). MOOCs and upskilling in Australia: A qualitative literature study. Cogent Education, 6(1), 1687392. https://doi.org/10.1080/2331186X.2019.1687392

Coleman, A., \& Zheng, G. (2020). Job-to-job transitions and the regional job-ladder (Working Paper 2020/01).

New Zealand Productivity Commission. https://www.productivity.govt.nz/assets/Documents/localgovernmentinsights-2/8c53ba315b/Job-to-job-transitions.pdf

Craig, R. (2015). College disrupted: The great unbundling of higher education. New York: St. Martin's Press. Dlabajová, M. \& Nekov, M. (2017). Report on a new skills agenda for Europe. 2017/2002(INI). European

Parliament. https://www.europarl.europa.eu/doceo/document/A-8-2017-0276_EN.pdf

Dorey, P. (2015) 'Well, Harold insists on having it!'-The political struggle to establish the Open University, 1965-67. Contemporary British History, 29(2) 241-272. https://doi.org/10.1080/13619462.2014.981160

Ehlers, U. (2020). Future Skills and the Future of Higher Education. International Council for Distance Education. https://nextskills.org/wp-content/uploads/2020/04/2020-01-ICDEFutureSkills.pdf

Epstein, J., \& Axtell, R. (1996). Growing Artificial Societies. Social Science from the Bottom Up. Brookins Institution Press/The MIT Press.

Ernst and Young. (2015). EY transforms its recruitment selection process for graduates, undergraduates and school leavers. http://www.ey.com/UK/en/Newsroom/News-releases/15-08-03-EY-transforms-itsrecruitment-selection-process-for-graduates-undergraduates-and-school-leavers

Expert Panel for the Review of the Australian Qualifications Framework (2019). Review of the Australian Qualifications Framework: Final report. Department of Education, Canberra.

Gallagher, S.R. (2016). The future of university credentials: New developments at the intersection of higher education and hiring. Harvard Education Press.

Gallagher, S. R. (2018). Educational credentials come of age: A survey on the use and value of educational credentials in hiring. Boston, MA: Northeastern University, Center for the Future of Higher Education and Talent Strategy. Retrieved from https://www.northeastern.edu/cfhets/wp- 
content/uploads/2018/12/Educational_Credentials_Come_of_Age 2018.pdf

Gilbert, N. \& Troitzsch, K. (2005). Simulation for the Social Scientist. Second edition. Open University Press, Milton Keynes.

Gu, X., Blackmore, K., Cornforth, D. \& Nesbitt, K. (2015). Modelling academics as agents: an implementation of an agent-based strategic publication model. Journal of Artificial Societies and Social Simulation, 18(2), 10.

Hadavand, A., Gooding, I., \& Leek, J. T. (2018). Can MOOC programs improve student employment prospects? https://doi.org/10.2139/ssrn.3260695

Hipkins, C. (2017). Making tertiary education and training affordable for all. Cabinet paper. New Zealand Government. https://www.education.govt.nz/assets/Documents/Ministry/Informationreleases/Making- tertiary-education-and-training-affordable-for-all.pdf

Huston, M., DeAngelis, D. \& Post, W. (1988). New computer-models unify ecological theorycomputer- simulations show that many ecological patterns can be explained by interactions among individual organisms. BioScience, 38(10):682-691. http://www.jstor.com/stable/1310870

Kato, S., Galán-Muros, V., \& Weko, T. (2020). The emergence of alternative credentials. OECD Education Working Papers 216. OCED Directorate for Education and Skills. https://dx.doi.org/10.1787/b741f39een

Kinash, S., \& Crane, L. (2015) Enhancing graduate employability of the 21st century learner [online].

Proceedings of the International Mobile Learning Festival 2015: Mobile Learning, MOOCs and 21st Century Learning. Hong Kong: International Mobile Learning Festival, pp. 148-171.

https://research.bond.edu.au/en/publications/enhancing-graduate-employability-of-the-21st-centurylearner

Mackintosh, W. (2016). OERu: Realising sustainable education futures. In F. Miao, S. Mishra \& R. McGreal (Eds.), Open educational resources: Policy, costs and transformation (pp. 129-146). Paris, France: United Nations Educational, Scientific and Cultural Organization.

Marshall, S. (2018) Shaping the University of the Future: Using Technology to Catalyse Change in University Learning and Teaching. Sydney, Australia: Springer. http://www.springer.com/gp/book/9789811076190

Maxwell, N. \& Gallagher, S. (2020). Drivers for change in higher education. New Directions for Community Colleges, 189, 9-22. https://doi.org/10.1002/cc.20394

McGreal, R., Mackintosh, W., \& Taylor, J. (2013). Open educational resources university: An assessment and credit for students' initiative. In R. McGreal, W. Kinuthia \& S. Marshall (Eds.), Open Educational Resources: Innovation, Research and Practice (pp. 47-62). Vancouver, Canada: Commonwealth of Learning and Athabasca University.

Milligan, S. \& Kennedy, G. (2017). To what degree? Alternative micro-credentialing in a digital age. Visions for Australian Tertiary Education, 41-53. https://melbourne-

cshe.unimelb.edu.au/data/assets/pdf_file/0006/2658444/MCSHE-Visions-for-Aust-Ter-Edweb2.pdf\#page $=49$

von Neumann, J. (1966). Theory of self-reproducing automata. University of Illinois Press. NZQA (2020a). Approval of micro-credentials. New Zealand Qualifications Authority.

https://www.nzqa.govt.nz/providers-partners/approval-accreditation-and-registration/micro-credentials/ NZQA (2020b). Understanding New Zealand qualifications. New Zealand Qualifications Authority.

https://www.nzqa.govt.nz/studying-in-new-zealand/understand-nz-quals/

Oliver, B. (2019). Making micro-credentials work for learners, employers and providers. Deakin University. http://dteach.deakin.edu.au/microcredentials/

Poundstone, W. (2012). Are you smart enough to work at Google? Trick questions, zen-like riddles, insanely difficult puzzles, and other devious interviewing techniques you need to know to get a job anywhere in the new economy. New York, NY: Little, Brown and Company.

Reardon, S., Kasman, M., Klasik, D. \& Baker, R. (2016). Agent-based simulation models of the college sorting process. Journal of Artificial Societies and Social Simulation, 19(1), 8. 
http://doi.org/10.18564/jasss. 2993

Schelling, T. C. (1969). Models of segregation. The American Economic Review, 59(2), 488-493. Schelling, T. C. (2006). Micromotives and macrobehavior. Revised Edition. WW Norton \& Company. Shah, D. (2019). By the numbers: MOOCs in 2019.

https://www.classcentral.com/report/mooc-stats-2019/

Thron, C. (2016). Lifestyle Tradeoffs and the Decline of Societal Well-Being: An Agent-Based Model. Journal of Artificial Societies and Social Simulation, 19(2), 5. http://doi.org/10.18564/jasss.3024

Wilensky, U. (1997). NetLogo Segregation model. Center for Connected Learning and Computer-

Based Modeling, Northwestern University. http://ccl.northwestern.edu/netlogo/models/Segregation

Wilensky, U. and Rand, W. (2015). An Introduction to Agent-Based Modeling: Modeling Natural, Social, and Engineered Complex Systems with NetLogo. The MIT Press.

Woodley, A. (2007). The UKOU: A model for the world? In D. Kember (Ed.), Reconsidering open and distance learning in the developing world: Meeting students' learning needs (pp. 29-60). Abingdon, UK: Routledge.

Zaber, M.A., Karoly, L.A. \& Whipkey, K. (2019). Reimagining the Workforce Development and Employment System for the 21st Century and Beyond. Rand Corporation. https://www.rand.org/pubs/research_reports/RR2768.html

Marshall, S. (2020). Modelling the impact of alternative educational qualifications on the New Zealand higher education system. In S. Gregory, S. Warburton, \& M. Parkes (Eds.), ASCILITE's First Virtual Conference. Proceedings ASCILITE 2020 in Armidale (pp. 344-354). https://doi.org/10.14742/ascilite2020.0141

Note: All published papers are refereed, having undergone a double-blind peer-review process.

The author(s) assign a Creative Commons by attribution licence enabling others to distribute, remix, tweak, and build upon their work, even commercially, as long as credit is given to the author(s) for the original creation.

(C) Marshall, S. 2020 